EGU21-10787

https://doi.org/10.5194/egusphere-egu21-10787

EGU General Assembly 2021

(c) Author(s) 2021. This work is distributed under

the Creative Commons Attribution 4.0 License.

\title{
Spatio-temporal evolution of afterslip following the Mw 7.8 Pedernales earthquake, Ecuador
}

\author{
Jean-Mathieu Nocquet ${ }^{1,2}$, Frederique Rolandone ${ }^{3}$, Patricia Mothes ${ }^{4}$, and Paul Jarrin ${ }^{3}$ \\ ${ }^{1}$ University Cote d'Azur, IRD, Geoazur, Valbonne, France (nocquet@geoazur.unice.fr) \\ ${ }^{2}$ University of Paris, Institut de Physique du Globe de Paris, Paris, France \\ ${ }^{3}$ Sorbonne University, ISTEP, Paris, France \\ ${ }^{4}$ Instituto Geofisico, Escuela Politecnica Nacional, Quito, Ecuador
}

We use 40 continuous GPS stations in Ecuador to quantify 3 years of the post-seismic deformation that followed the Mw 7.8 April 16 Pedernales earthquake. We perform a kinematic inversion solving for the daily slip along the subduction to retrieve the afterslip evolution through time and space.

Rolandone et al. (2018) had found that the afterslip during the first 30 days following the earthquake was abnormally large and rapid, mainly developing at discrete patches north and south updip of the co-seismic rupture. We find that large slip and slip rate continue at both location, decreasing through time. However, models suggest that modulations of slip rate occur within those areas, with episods of slip acceleration sometimes associated with the occurrence of moderate size aftershocks. Aside these patches, afterslip developed updip the co-seismic rupture between the patches and downdip of the coseismic rupture, with little slip occurring within the coseismic rupture.

The overall model confirms a model of a seismic asperity encompassed in a subduction interface releasing stress through aseismic processes. However, some areas experiencing afterslip appear to be locked before the earthquake. Furthermore, those areas experienced SSE before the earthquake and during the afterslip period, raising the question of the friction parameter controlling their behavior.

In terms of moment, the amount of afterslip after 3 years is equivalent to $90 \%$ of the moment released by the Pedernales earthquake. This observation highlights that aseismic slip has an important contribution to the balance of slip during the earthquake cycle along the central Ecuador segment. This observation strengthens the proposed hypothesis of earthquake an supercycle in central Ecuador (Nocquet et al., 2017), by confirming that the occurrence of three successive major earthquakes within 110 years exceeds the moment accumulation as derived from a decade of interseismic coupling models spanning a decade before the 2016 earthquake. 